\title{
Original Article \\ Factors Influencing Annual Procurement Planning of Medicines and Medical Supplies in Public Health Facilities in Kampala District
}

Martha Grace Ajulong1*, John Charles Okiria², Martin Owako²

${ }^{1}$ EAC Regional Centre of Excellence for Vaccines, Immunization, and Health Supply Chain Management, College of Medicine and Health Sciences, University of Rwanda, Kigali, Rwanda. ${ }^{2}$ Makerere University, Kampala, Uganda

*Corresponding author: Martha Grace Ajulong. EAC Regional Centre of Excellence for Vaccines, Immunization, and Health Supply Chain Management, College of Medicine and Health Sciences, University of Rwanda, Kigali, Rwanda. Email:mge32@hotmail.com

\section{Abstract}

\section{Background}

Despite significant progress made by many countries towards meeting the millennium development goals and now sustainable development goals, there has been little improvement in access to essential medicines in developing countries.

\section{Objectives}

The main aim of this study is to assess the factors influencing annual procurement planning of medicines and medical supplies in the public health facilities in Kampala district.

\section{Methods}

This study targeted respondents from government Health facilities in Kampala with a total population of 424 employees and applied simple random sampling to select 206 health workers. The researcher adopted mixed research approach with application of descriptive statistics, correlational and explanatory research designs that were used to maximize reliability and validity of findings. While the qualitative data was gathered through reviewing logistics tools, a physical count of the 30\% purposively selected stock cards and interview of the staffs was carried out in health facilities in Kampala district, a Statistical Package for Social Science (SPSS) version 20 was used to analyze the quantitative data. Accordingly, a chi-square was used to determine the association between independent and dependent variables.

\section{Results}

The findings indicated that $37.8 \%$ of the staff responded positively about the availability of annual procurement plan while the rest were from various health facilities. A significant association was observed between knowledge and availability of annual Procurement planning $\left(\mathrm{X}^{2}=34.7 ; \mathrm{p}\right.$ value $\left.=.0001\right)$, as well as management support and Annual Procurement Planning $\left(\mathrm{X}^{2}=9.87 ; \mathrm{P}\right.$ value $\left.=.008\right)$.

\section{Conclusion}

In conclusion, the finding generated from analysis of quantitative and qualitative data revealed that a majority of the factors influencing annual procurement planning had a positive effect on medical supplies in public health facilities in Uganda although the capacity and capability of health workers, quality of logistics management information systems, and management support desires improvement.

Rwanda J Med Health Sci 2021;4(2): 292-309

Keywords: Public health facilities, Annual Procurement planning, essential medicines 


\section{Background}

Availability of essential medicines and medical supplies is a major determinant of quality of health care in a given country. Despite significant progress made by many countries towards meeting the millennium development goals and now sustainable development goals, there has been little improvement in access to essential medicines in developing countries.[1] In developing countries like Uganda and Kenya, poor procurement planning has been one of the major stumbling blocks to the economic development of Africa and it has been clear that a number of African countries have not paid adequate attention to the proper management of public resources.[2] Although Uganda has increased funding to the health sector mainly from the donors, poor management of scarce resources arising from poor planning has led to problems of stock outs and expensive emergency procurements.[3]

Annual Procurement plans (APPs) provide information on significant procurement entities plan to be undertaken over the next twelve months. The APPs is an annual document which defines the products and services that a public body will obtain from external suppliers. Additionally, a sound procurement plan helps a procuring entity to define their procurement requirements and to decide where and when to procure.[4]

Annual procurement planning of medicines and medical supplies involves a proactive and phased approach to management of a facilities procurement process so as to achieve overall objectives of agreed procurement policies. The process also involves reviewing of Stock cards, stock books, in-patient files on an annual basis in order to determine the quantities of items that can be planned and procured in the next financial year. Annual procurement plans for medicines and medical supplies are planned for before the financial budget is read.

On the contrary, there are a number of factors that affect procurement planning. Inadequate competencies of procurement staff, lack of management support, information technology tools and budgeting procedures affect procurement planning. For some years now, almost all public health facilities in Uganda did not know how to prepare annual procurement plan for medicines and medical supplies and vaccines. This was attributed to lack of set rules, procedures and principles to follow during procurement planning process and the people involved in procurement planning were non pharmacists, pharmacy technicians and public nurses for immunization. More so, there was lack of knowledge on availability of allocated funds in the budget on time and some items to procure not indicated in the budget. These resulted into loss of value for money, procurement of unnecessary items which were not needed in much quantities and also expiries of health commodities.[5]

Therefore, the Ugandan government decided to allocate resources to the Ministry of Health, Pharmacy division, and hired a consultant in procurement planning to support and train people on 
procurement planning in order to obtain value for money by planning for the right health commodities. Despite the efforts made by both government and implementing partners, there are still many challenges of procurement planning in the public health facilities.[5] This study will therefore contribute information necessary for establishing factors affecting procurement planning which will help government in designing policies and effective strategies to address the existing challenges.

Generally, no stand-alone research has been done regarding annual procurement planning of medicines and medical supplies and vaccines in Uganda. In Kenya studies that have been conducted are specifically about general procurement planning and nothing has been mentioned about annual procurement planning of medicines and medical supplies and vaccines.[6] However, the requirement for procuring health facilities to prepare annual procurement plans in Uganda is mandatory in accordance with the public procurement Act no. 293 of 2003. Moreover, many public health facilities do not give proper attention to preparing the annual procurement plans. Notably, a properly prepared and vetted annual procurement plan is also a pre-requisite for proper national procurement planning. The National Medical Stores (NMS) consolidates procurement plans from different health facilities to constitute a national procurement plan that informs the procurement of medicines and health supplies. Hence a poor annual procurement plan from a health facility not only affects supply of medicines and health supplies to that facility but also the entire health of the given nation.

In Uganda, many public health facilities are faced with the problem of partly improper development of annual procurement plans leading to increased stock outs of medicines and medical supplies.[3] Staff from public health facilities in Uganda have failed to answer basic questions on how to determine procurement quantities such as what is average monthly consumption (AMC), what to order, what quantity to order and when to order.[3] Ineffective Annual procurement planning of EMHS, vaccines pose a big challenge to public health facilities in Kampala city, therefore the study aims to assess the factors that affect procurement planning in Kampala city. Knowledge about these factors is important in forming interventions to improve the quality of procurement plans and eventually availability and access to medicines and health supplies. Thus, the main objective of this study is to assess the factors influencing annual procurement planning of medicines and medical supplies in the public health facilities in Kampala district, Uganda. This main research objective can be fulfilled by achieving the following specific objectives: a) to assess the capacity of health facility staff in procurement planning of medicines and medical supplies in Kampala District; b) to identify the logistics management information system (LMIS) tools used in the annual procurement planning of medicines and medical supplies in Kampala district; and c) to determine the management support systems that 
is used in annual procurement planning of medicines and medical supplies in Kampala district.

The Conceptual Framework Independent variable

\section{Dependent variable}

\section{Capacity of health workers}

- Knowledge about budget

- Coordination between departments

- Competent professional workforce

- Knowledge about APP

\section{Logistics Management Information} Systems

- Equipment at the department

- Records management

\section{Management Support}

- Effective supportive supervision

- Functional APP

- Functional Medicines therapeutic committee

and

- Training of staff in APP

- Standard operating Procedures for APP

- Institutional formulary

- Availability of UCGs

- Feedback to staffs on the APP

- Human resources 


\section{Methods}

\section{Study setting}

Kampala is the capital and largest city of Uganda. The city is divided into five boroughs that oversee local planning: Kampala Central Division, Kawempe Division, Makindye Division, Nakawa Division, and Lubaga Division. Surrounding Kampala is the rapidly growing Wakiso District, whose population more than doubled between 2002 and 2014 and now stands at over 2 million. Kampala city was chosen for the study because it is the capital city of Uganda and despite the increase in the number of National Referral Hospitals and Health Centre 1Vs and IIIs to decongest the two (2) official National Referral Hospitals, Mulago National referral Hospital and Butabika National Psychiatric hospital, little impact has been felt from these public facilities since they continue to experience issues of EMHS stock outs. Therefore, this study has been conducted to so that factors affecting APP in public health facilities in Kampala city are established. The HCIV's in Kampala city where study was carried out include: Kisenyi, and Murchison Bay. The HCIII's included, Kiswa, Kawala, and Komamboga. In addition to Mulago and Butabika national referral hospitals, while the other National referral Hospitals where the study was carried out included Kawempe, Kiruddu, and Murchison Bay Referral Hospital.

\section{Study approach and design}

This study adopted a mixed method research approach with application of descriptive and correctional research designs which permits the researcher to collect data at particular point in time and it is not time wasting. The study tends to achieve the study objectives by linking the independent variable to the dependent variable as shown in the conceptual frame work above. On the other hand, qualitative data was analyzed using explanatory research design and deductive technique in particular.

\section{Study population and sampling}

A total of 206 respondents were selected from a population of 424 health workers operating from different levels of government health care facilities that is to say; National Referral Hospitals, Health center $1 \mathrm{~V}$ and Heath Centre 111. The staff of the National Referral Hospitals were purposively selected. Mulago National Referral Hospital was omitted to avoid bias because the researcher works at Mulago National referral Hospital. The National Referral Hospitals, Health Centre 1Vs and Health Center 111s were selected using simple random sampling. This was done by writing the names of the facilities in small papers, put them in a basket and randomly picked the required number of facilities. While the health workers involved in APP were purposively selected and simple random sampling was used for facilities where the health workers are very many to determine the number required.

\section{Data collection instruments and procedure}

The data collection instruments used were a questionnaire and document review. The survey questionnaire was 
developed based on the APP activities at the pharmacy department in the health facility and the study variables. The selfadministered questionnaires contained information on existing procurement planning activities; annual procurement process data tools used for annual procurement and available supply chain human resources. Suggestions for solutions were captured by the research instrument. Ample time to analyze and answer questions was done by respondents as the information was obtained. The questionnaire was semistructured. The document review used was to obtain information about the LMIS tools. The document review required to purposively select $30 \%$ of the stock cards in all the facilities that the study was carried out from.

\section{Data analysis}

This study adopted descriptive statistics and correlational research designs to analyze the quantitative data and used SPSS V20 software to establish the univariate values of frequency and percentages which was inadequate to make conclusions. Consequently, bivariate analysis was used to relate independent and dependent variables with application of chi-square to establish the strength of their relationship hence making meaningful conclusions and recommendations.

\section{Ethical Consideration}

The study permission and approval were obtained from Institutional Review Board (IRB) School of health Sciences Research and ethics Committee College of Health Sciences. Permission to conduct the study for Health Centre IVs was obtained from Directors Kampala Capital City Authority (KCCA) /incharges of the Health Facilities. Data for Murchison Referral Hospitals was obtained from Head Research Prison Services. The researcher observed all the principles of research ethics such confidentiality and informed consent.

\section{Results}

\section{Demographic characteristics of respondents}

Majority of the study respondents were health workers from the National referral hospitals 90(43.7\%), followed by the Health Centre IV 65(31.6\%) and Health Centre III with 51(24.8\%). By qualification, pharmacy technicians, 85 (41.3\%), were the majority, followed by the nurses, 61(29.6\%). The majority, $82(39.8 \%)$, of the health workers had been in the respective health facilities for more than 5 years and most of them held positions as pharmacy in-charge $89(43.2 \%)$. 
Table 1. Demographic characteristics of respondents

\begin{tabular}{lll}
\hline Variables & $\begin{array}{l}\text { Frequencies } \\
\text { (n=206) }\end{array}$ & Percentages (100\%) \\
\hline Level of health facility & 51 & 24.8 \\
Health center lll & 65 & 31.6 \\
Health facility IV & 90 & 43.7 \\
National referral hospital & 206 & 100.0 \\
Total & & \\
\hline Qualification of the respondents & 24 & 11.7 \\
Medical doctor & 85 & 41.3 \\
Pharmacy technician & 36 & 17.5 \\
Procurement officer & 61 & 29.6 \\
Nurse & 206 & 100.0 \\
Total & & \\
\hline How long served in the facility & 71 & 34.5 \\
Less than 2 years & 53 & 25.7 \\
2-4years & 82 & 39.8 \\
5 or more & 206 & 100.0 \\
Total & & \\
\hline Position in the facility & 48 & 23.3 \\
In charge for facility & 69 & 33.5 \\
store in charge & 89 & 43.2 \\
pharmacy in charge & 206 & 100.0 \\
Total &
\end{tabular}

\section{Description of the demographic data of respondents}

As shown in Table 2 below, the majority, $56(37.8 \%)$, of the health workers who responded positively about the availability of the Annual Procurement Plan were from the National Referral hospitals and a reasonable number of other health workers from various health facilities also responded positively about the availability of the Annual Procurement Plan. The chisquare value of 26.576 was produced with the $\mathrm{P}$-value of 0.0001 giving the implication that, there is a statistical significance between level of health facilities and the availability of the annual procurement plan.

Majority of the health workers who responded positively about the availability of the Annual procurement plan were the pharmacy technicians, $68(45.9 \%)$. However, equally many of health workers of other qualifications responded positively about the availability of the annual procurement plan. A chi-square value of 22.446 and p-value of 0.0001 were produced implying that there is a strong statistical association between health workers qualification and the availability of annual procurement plan. The duration 
of services by health workers in the health care facilities was found statistically significantly associated with the availability of annual procurement plan. This was evidenced by the chisquare value of 34.487 and the significance value of 0.0001 .

Table 2. Demographics of health workers and Annual Procurement Plan

\begin{tabular}{|c|c|c|c|c|}
\hline \multirow[t]{2}{*}{ Variable } & \multicolumn{4}{|c|}{$\begin{array}{l}\text { Presence of Annual } \\
\text { procurement plan }\end{array}$} \\
\hline & Yes & No & $\begin{array}{l}\text { Chi-square } \\
\text { value }\end{array}$ & $\begin{array}{l}\text { P- } \\
\text { value }\end{array}$ \\
\hline \multicolumn{5}{|l|}{ Level of health facility } \\
\hline Health center 111 & $51(34.5 \%)$ & $0(0.0 \%)$ & 26.576a & 0.0001 \\
\hline Health facility IV & $41(27.7 \%)$ & $24(41.4 \%)$ & & \\
\hline National referral hospital & $56(37.8 \%)$ & $34(58.6 \%)$ & & \\
\hline Total & 148 & 58 & & \\
\hline \multicolumn{5}{|l|}{ Position in the facility } \\
\hline In charge for facility & $45(30.4 \%)$ & $3(5.2 \%)$ & 27.517a & 0.009 \\
\hline store in charge & $35(23.6 \%)$ & $34(58.6 \%)$ & & \\
\hline pharmacy in charge & $68(45.9 \%)$ & $21(36.2 \%)$ & & \\
\hline Total & 148 & 58 & & \\
\hline \multicolumn{5}{|c|}{ Qualification of the respondents } \\
\hline medical doctor & $24(16.2 \%)$ & $0(0.0 \%)$ & $22.446 a$ & 0.0001 \\
\hline pharmacy technician & $68(45.9 \%)$ & $17(29.3 \%)$ & & \\
\hline procurement officer & $19(12.8 \%)$ & $17(29.3 \%)$ & & \\
\hline Nurse & $37(25.0 \%)$ & $24(41.4 \%)$ & & \\
\hline Total & 148 & 58 & & \\
\hline \multicolumn{5}{|c|}{ How long have you served in the facility } \\
\hline less than 2 years & $37(25.0 \%)$ & $34(58.6 \%)$ & $34.487 a$ & 0.0001 \\
\hline 2-4years & $53(35.8 \%)$ & $0(0.0 \%)$ & & \\
\hline 5 and more & $58(39.2 \%)$ & $24(41.4 \%)$ & & \\
\hline Total & 148 & 58 & & \\
\hline
\end{tabular}

\section{Capacity of health workers}

As shown in Table 3, the majority, 128 (86.5\%), of the health worker who were involved in the annual procurement plan responded positively about its availability than those who were not. The chi- square value of 65.356 and the significance value of 0.0001 . This gave am implication that involving health workers in the procurement plan had a strong statistical significance. The biggest percentage of health workers who had knowledge on why procurement plan is done annually responded positively about its availability. The chi-square value of 47.339 and $p$-value of 0.0001 were produced giving an implication that there is a statistical significance between knowledge and availability of annual procurement plan. 
Table 3. Capacity of health workers to conduct Annual Procurement Plan

\begin{tabular}{|c|c|c|c|c|}
\hline \multicolumn{5}{|c|}{ Presence of Annual procurement plan } \\
\hline Variable & Yes & No & $\begin{array}{l}\text { Chi-square } \\
\text { value }\end{array}$ & P-value \\
\hline \multicolumn{5}{|c|}{ Health workers involved in the APP } \\
\hline Yes $\quad 1$ & $128(86.5 \%)$ & $17(29.3 \%)$ & $65.356 a$ & 0.0001 \\
\hline No & $20(13.5 \%)$ & $41(70.7 \%)$ & & \\
\hline Total & 148 & 58 & & \\
\hline \multicolumn{5}{|c|}{ When are health workers involved in APP } \\
\hline Never & $20(13.5 \%)$ & $0(0.0 \%)$ & 28.135a & 0.0001 \\
\hline $\begin{array}{l}\text { Beginning of the } \\
\text { year }\end{array}$ & $111(75.0 \%)$ & $34(58.6 \%)$ & & \\
\hline End of the year & $17(11.5 \%)$ & $24(41.4 \%)$ & & \\
\hline Total & 148 & 58 & & \\
\hline \multicolumn{5}{|c|}{ Health worker's knowledge on why is APP done. } \\
\hline $\begin{array}{l}\text { To improve quality } \\
\text { of commodities }\end{array}$ & $90(60.8 \%)$ & $24(41.4 \%)$ & 47.339a & 0.0001 \\
\hline $\begin{array}{l}\text { To match the } \\
\text { budget allocated }\end{array}$ & $58(39.2 \%)$ & $17(29.3 \%)$ & & \\
\hline Do not know & $0(0.00 \%)$ & $17(29.3 \%)$ & & \\
\hline Total & 148 & 58 & & \\
\hline
\end{tabular}

Logistics Management Information System Tools of the APP

As shown in Table 4 on the use of Logistics Management Information systems in annual procurement planning it was found out that majority of the health workers $141(68.4 \%)$ knew that we use stock book and stock a card during APP, in regards to actual use of stock book during APP 131(63.6\%) reported that they do not use the stock book in APP, and regarding health workers not using LMIS tools during Annual Procurement Planning $51(24.8 \%)$ stated that the stock book is not updated while $41(19.9 \%)$ reported that they do not know.

Table 4. Logistics Management Information System in the annual procurement planning

\begin{tabular}{lll}
\hline Variables & Frequencies & Percentages \\
& $(\mathbf{n}=206)$ & $(100 \%)$ \\
\hline
\end{tabular}

What LMIS tools do you use to get information during procurement plan

$\begin{array}{lll}\text { Stock card and book } & 141 & 68.4 \\ \text { Outpatient register } & 24 & 11.7 \\ \text { Previous procurement plan } & 24 & 11.7 \\ \text { Do not know } & 17 & 8.3 \\ \text { Total } & 206 & 100.0\end{array}$

Do you use the information from stock book in procurement plan? 


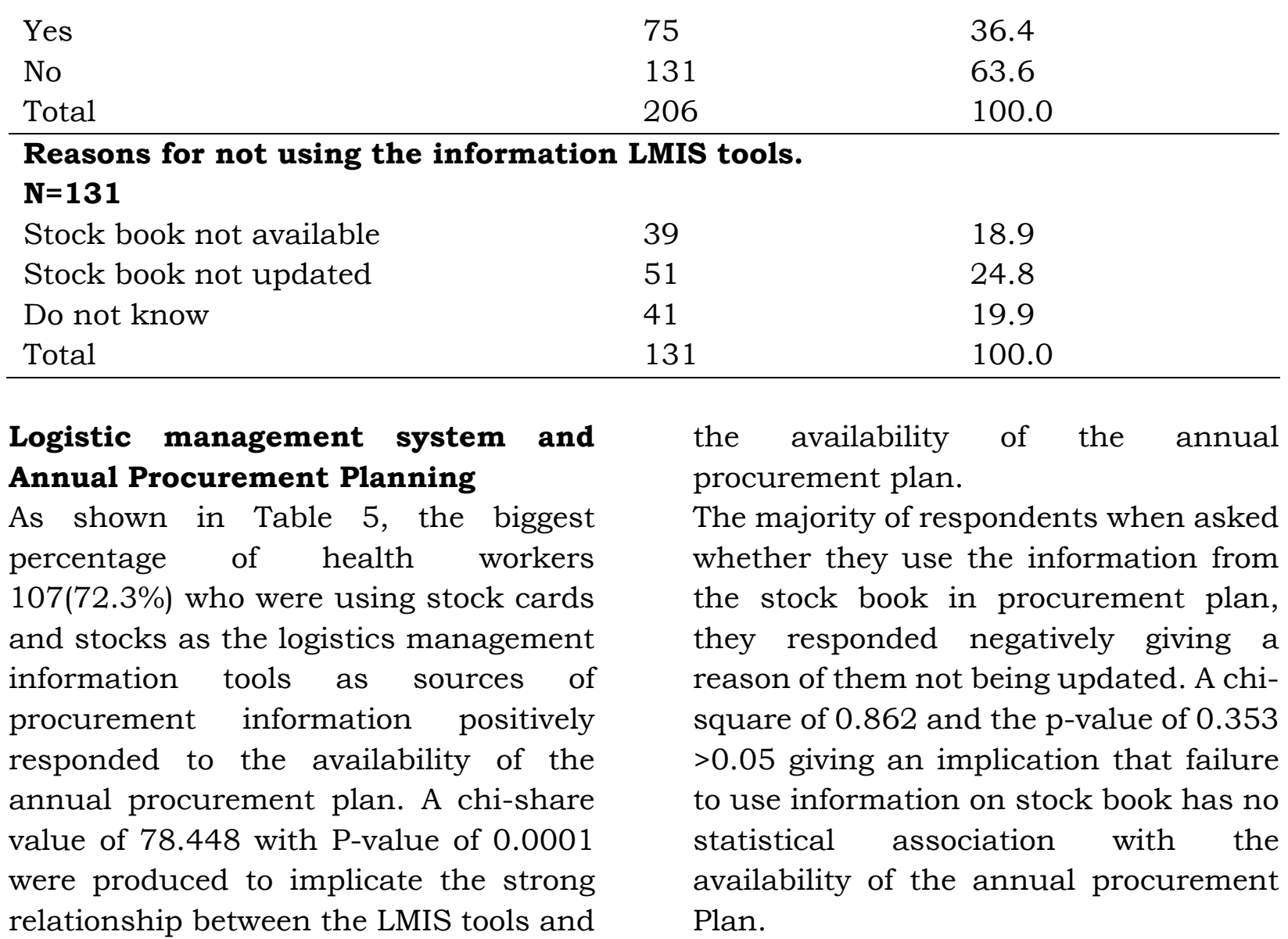

Table 5. Logistic Management System and Annual Procurement Planning

\begin{tabular}{|c|c|c|c|c|}
\hline \multicolumn{5}{|c|}{ Presence of Annual procurement plan } \\
\hline Variable & Yes & No & $\begin{array}{l}\text { Chi-square } \\
\text { value }\end{array}$ & P-value \\
\hline \multicolumn{5}{|c|}{ What LMIS tools do you use to get information during procurement plan } \\
\hline $\begin{array}{l}\text { Stock card and } \\
\text { book }\end{array}$ & $107(72.3 \%)$ & $34(58.6 \%)$ & 78.448a & 0.0001 \\
\hline Outpatient register & $0(0.0 \%)$ & $24(41.4 \%)$ & & \\
\hline $\begin{array}{l}\text { Previous } \\
\text { procurement plan }\end{array}$ & $24(16.2 \%)$ & $0(0.0 \%)$ & & \\
\hline Do not know & $17(11.5 \%)$ & $0(0.0 \%)$ & & \\
\hline Total & 148 & 58 & & \\
\hline \multicolumn{5}{|c|}{ Health workers usage of the information from stock book in procurement pla } \\
\hline Yes & $51(34.5 \%)$ & $24(41.4 \%)$ & $0.862 a$ & 0.353 \\
\hline No & $97(65.5 \%)$ & $34(58.6 \%)$ & & \\
\hline Total & 148 & 58 & & \\
\hline
\end{tabular}


Management support in Annual Procurement Planning

As shown in Table 6, regarding management support, 131(63.9\%) reported that the facility in-charge does not disseminate information regarding the budget, $114(55.3 \%)$ indicated that procurement planning meetings are held once a year, 61(29.6\%) that they did not know the kind of meeting that were held, $165(80.1 \%)$ implied that there were no minutes kept, 135(65.5\%) indicated that there were no operational Medicines and Therapeutic Committees at the facility, $19(9.2 \%)$ that reported availability of Medicines and Therapeutic Committee did not know their roles in MTC, 111(53.9\%) that reported unavailability of MTC, reported that they have Procurement Planning committee instead of $\mathrm{MTC}$, in rating of management support 95(46.1\%) rated it as fair while $60(29.1 \%)$ rated management support as poor, 65(31.6\%) reported not getting any support from management,128(62.1\%) reported that all the above mentioned cadres are involved in the APP,44(21.4\%) of the health workers reported not knowing who should be involved in APP and in regards to support from management support $206(100 \%)$ of the health workers reported that they needed support from management.

Table 6. Management support and Annual Procurement Planning

\begin{tabular}{llc}
\hline Variables & $\begin{array}{l}\text { Frequencies } \\
(\mathbf{n = 2 0 6 )}\end{array}$ & $\begin{array}{l}\text { Percentages } \\
(\mathbf{1 0 0 \% )}\end{array}$ \\
\hline $\begin{array}{l}\text { Dose the facility in charge disseminates the information on budget allocated for } \\
\text { medicines }\end{array}$ & 75 & 36.4 \\
Yes & 131 & 63.6 \\
No & 206 & 100.0 \\
Total & &
\end{tabular}

How many procurement plan meetings do you conduct for specific procurement period

once a year

$114 \quad 55.3$

twice a year

$\begin{array}{ll}75 & 36.4\end{array}$

Other

17

8.3

Total

206

100.0

What kind of meetings do you hold

Entry procurement planning meeting

$58 \quad 28.2$

Review of procurement plan

$87 \quad 42.2$

Do not know

61

29.6

Total

206

100.0

Do you have minutes for the procurement plan meetings

Yes

41

19.9

No

165

80.1

Total

206

100.0

Do you have operational medicines and therapeutic committee? Yes 17

8.3

No 135

65.5 


\begin{tabular}{lcc}
\hline Do not know & 54 & 26.2 \\
Total & 206 & 100.0 \\
\hline If yes, what is the role of MTC & \\
constitutes the procurement plan & 17 & 8.3 \\
None & 19 & 9.2 \\
\hline If no MTC, do you have procurement planning committee? & \\
Yes & 111 & 53.9 \\
No & 95 & 46.1 \\
Total & 206 & 100.0 \\
\hline How do you rate the support from management during the procurement planning \\
Very good & 51 & 24.8 \\
Fair & 95 & 46.1 \\
Poor & 60 & 29.1 \\
Total & 206 & 100.0 \\
\hline What kind of support do you get from management & \\
Facilitation of procurement planning & 34 & 16.5 \\
meetings & & \\
Ensuring availability of information for PP & 17 & 8.3 \\
Budgeting for PP activities & 17 & 8.3 \\
All above & 73 & 35.4 \\
None & 65 & 31.6 \\
Total & 206 & 100.0 \\
\hline
\end{tabular}

Majority of Health workers when asked whether they're in charges disseminate the information on budget allocated for medicines they responded negatively $58(100.0 \%)$. A chi-square of 46.219 and the $\mathrm{p}$-value of $0.0001<0.05$ giving an implication having no information on budget allocated for medicines has a strong statistical association with the availability of the annual procurement Plan.

The biggest proportion of health workers held various meetings such as Entry procurement planning meeting, review of procurement plan meeting. When they asked whether they receive minutes for these meetings majority 107(72.3\%) responded negatively. A chi-square of 20.060 and the $p$-value of $0.0001<0.05$ this gave an implication that having no meeting minutes has a strong statistical association with the availability of the annual procurement Plan

Majority of health workers $77(52.0 \%)$ when asked about the presence of operational medicines and therapeutic committee responded negatively. The evidence of the chi-square value $77(52.0 \%)$ and $p$-value of $0.0001<0.05$ implied that the absentia of the operational medicines and therapeutic committee had a statistical significance to the availability of the annual procurement Plan

The biggest number of health workers rated the support from management during the procurement planning as fair 
$78(52.7 \%)$ and others reasonable number rated it poor 24(41.4\%). The chisquare value of 9.782 and $p$-value of $0.008<0.05$ implied that the management support in them of facilitation of procurement planning meetings, ensuring availability of information for Procurement Plan and Budgeting for Procurement Plan activities were strongly associated to the availability of the annual procurement Plan.

Table 7. Management support to health workers in Annual Procurement Plan Availability of Annual procurement plan

\begin{tabular}{|c|c|c|c|c|}
\hline Variable & Yes & No & $\mathbf{X}^{2}$ & P-value \\
\hline \multicolumn{5}{|c|}{ Dissemination the information on budget allocated for medicines } \\
\hline Yes & $75(50.7 \%)$ & $0(0.0 \%)$ & $46.219 a$ & 0.001 \\
\hline No & $73(49.3 \%)$ & $58(100.0 \%)$ & & \\
\hline Total & 148 & 58 & & \\
\hline \multicolumn{5}{|c|}{ Kind of meetings do you hold } \\
\hline $\begin{array}{l}\text { Entry } \\
\text { procurement } \\
\text { planning meeting }\end{array}$ & $58(39.2)$ & $0(0.0 \%)$ & $31.639 a$ & 0.001 \\
\hline $\begin{array}{l}\text { Review of } \\
\text { procurement plan }\end{array}$ & $53(35.8 \%)$ & $34(58.6 \%)$ & & \\
\hline Do not know & $37(25.0 \%)$ & $24(41.4 \%)$ & & \\
\hline Total & 148 & 58 & & \\
\hline \multicolumn{5}{|c|}{ Having minutes for the procurement plan meetings } \\
\hline Yes & $41(27.7 \%)$ & $0(0.0 \%)$ & $20.060^{a}$ & 0.000 \\
\hline No & $107(72.3 \%)$ & $58(100 \%)$ & & \\
\hline Total & 148 & 58 & & \\
\hline \multicolumn{5}{|c|}{ Presence of operational medicines and therapeutic committee } \\
\hline Yes & $17(11.5 \%)$ & $0(0.0 \%)$ & 42.458 & 0.0001 \\
\hline No & $77(52.0 \%)$ & $58(100 \%)$ & & \\
\hline Do not know & $54(36.5 \%)$ & $0(0.0 \%)$ & & \\
\hline Total & 148 & 58 & & \\
\hline
\end{tabular}

Source: Field data 
Table 8. Management support to health workers and APP

\begin{tabular}{|c|c|c|c|c|}
\hline \multicolumn{5}{|c|}{ Availability of Annual procurement plan } \\
\hline Variable & Yes & No & $\mathbf{X}^{2}$ & P-value \\
\hline \multicolumn{5}{|c|}{ Support from management during the procurement planning } \\
\hline Very good & $34(23 \%)$ & $17(29.3 \%)$ & $9.782^{\mathrm{a}}$ & 0.008 \\
\hline Fair & $78(52.7 \%)$ & $17(29.3 \%)$ & & \\
\hline Poor & $36(24.3 \%)$ & $24(41.4 \%)$ & & \\
\hline Total & 148 & 58 & & \\
\hline \multicolumn{5}{|c|}{ Kinds of support health workers get from management } \\
\hline $\begin{array}{l}\text { Facilitation of } \\
\text { procurement } \\
\text { planning meetings }\end{array}$ & $34(23 \%)$ & $0(0.0 \%)$ & $80.049 a$ & 0.0001 \\
\hline $\begin{array}{l}\text { Ensuring availability } \\
\text { of information for PP }\end{array}$ & $17(11.5 \%)$ & $0(0.0 \%)$ & & \\
\hline $\begin{array}{l}\text { Budgeting for } \mathrm{PP} \\
\text { activities }\end{array}$ & $0(0.0 \%)$ & $17(29.3 \%)$ & & \\
\hline All above & $56(37.8 \%)$ & $17(29.3 \%)$ & & \\
\hline None & $41(27.7 \%)$ & $24(41.4 \%)$ & & \\
\hline & 148 & 58 & & \\
\hline
\end{tabular}

\section{Discussion}

The study found a statistical significance between level of health facilities and the availability of the annual procurement planning for medicines and supplies. This therefore, informs the heads of these respective health facilities to always consider annual procurement plans as an important aspect of improving availability of medicines and medical supplies thus improving the quality of life of the general population.

As we focus on improving the procurement planning of medicine and supplies, there is need to involve all health workers of various qualifications in procurement process say the pharmacy technician, doctors, nurses, store managers and many more as their contributions are equally important to the success of effective medicine supply chain. This was evidenced in these very study findings where it was revealed that involving health workers in the procurement plan had a strong statistical significance. This is in agreement with a study conducted in Kenya [5] which found that inadequate competencies of procurement staff, lack of management support, information technology tools and budgeting procedures affect procurement planning.

This study is also in agreement with the findings that were got in Namibia on capacity of health workers handling procurement planning, where the study revealed that inadequate capacity and information hampered procurement planning and quantification and inventory control systems in the supply chain were weak.[6] Similarly, this study 
is in agreement with the study results found in Rwanda regarding capacity of health workers in procurement planning in Rwanda it was found that a lack of capacity existed to quantify and coordinate needs for Prevention of Mother to child transmission (PMTCT) and Antiretroviral Therapy (ART) services.[6]

This is in agreement with a study carried out in Uganda, some years ago that almost all public health facilities in Uganda did not know how to prepare annual procurement plan for medicines and medical supplies and vaccines. This was attributed to lack of set rules, procedures and principles to follow during procurement planning process and the people involved in procurement planning were non pharmacists, pharmacy technicians and public nurses for immunization. More so, there was lack of knowledge on availability of allocated funds in the budget on time and some items to procure not indicated in the budget. These resulted in to loss of value for money, procurement of unnecessary items which are not needed in much quantities and also expiries of health commodities.[7]

Health workers equally need to be empowered with knowledge on why procurement planning of medicines and other supplies are done annually so as to improve on the availability of essential medicines and other health supplies. This is in agreement with the study findings where it was found that, health workers who had knowledge on why procurement planning was done annually were more involved in the procurement plan and were much willing to support the process than those who did not know. Another study also in agreement with this study finding when they found that a sound Annual Procurement Planning system has to have a competent professional workforce equipped with defined skills and knowledge for specified procurement jobs.[8]

\section{Logistics Management Information systems and Annual Procurement Planning of Medicines and Medical supplies.}

The routine proper usage of logistics management information tools such as the stock cards and stock books as sources of procurement information are key in successful annual procurement planning of medicines and other health supplies. This was best revealed in the study findings where a strong statistical relationship between the LMIS tools and the availability of the annual procurement plan. This is in agreement with a research conducted in Tanzania and Zambia which found that an effective logistics management information system (LMIS) should ensure that adequate quantity and quality of health commodities are always available at the point of service to meet patient demand.[10]

For these tools to be useful for annual procurement planning of medicines and other health supplies, they are required to be updated regularly by the health care professionals of concern. 


\section{Management Support and Annual Procurement Planning of Medicines and Medical supplies}

The study revealed that it is important to have information about the budget, entry, exit and review meetings are important in Annual Procurement planning of medicines and medical supplies. It was also noted that minute keeping is quite important for future reference. This study also reveals that it is important to have an operational MTC, since MTC are the ones that are involved in vetting the Annual Procurement plan before it is approved by the facility in-charge. There is also need for great management support from management so as to improve annual procurement planning. This is in agreement with a study in Kenya [7] which found that inadequate competencies of procurement staff, lack of management support, information technology tools and budgeting procedures affect procurement planning.

\section{Conclusion}

The results of this study indicated that there is a statistical significance between knowledge or capacity of health workers and availability of annual procurement plan. The study outcome further revealed that availability of annual procurement plans in the facilities was promising yet the capacity and capability of health workers, quality of logistics management information systems, and management support desires improvement. A strong relationship between the LMIS tools and the availability of the annual procurement plans was reported. Besides, the availability of APP was statistically associated with management support in terms of facilitation of procurement planning meetings, ensuring availability of information for procurement plan and budgeting for procurement plan activities.

Based on current results, we conclude that in order to attain this healthcare system block there is need to improve capacity of health workers through training, imparting knowledge. Additionally, management support activities such as meetings, keeping of minutes of annual procurement planning meetings and ensuring functionality of Medicines and therapeutic committees in the health facilities are all very important.

\section{Recommendations}

It is recommended for the Ministry of Health to: strengthen medicines and therapeutic committees in the health facilities; ensure availability of policies on annual procurement planning, avail policies to the health facilities; ensure that logistics management information tools are in use and available; ensure that the health workers are trained in annual procurement planning, logistics management information systems tools, and ensure to always have meetings, keep meetings of annual procurement planning of medicines and medical supplies for future reference.

\section{Conflict of interest}

All authors report no conflict of interest. 


\section{Acknowledgement}

The authors of this paper gratefully acknowledge the funding of the Masters of Health Supply Chain Management by the German Federal Ministry for Economic Cooperation and Development (BMZ) through KfW Development Bank and the East African Community Regional Center of Excellence for Vaccines, Immunization, and Health Supply Chain Management. In addition, this research would not have been possible without the assistance of the College of Medicine and Health Sciences, University of Rwanda.

This article is published open access under the Creative Commons Attribution-Non-Commercial No Derivatives (CC BYNC-ND4.0). People can copy and redistribute the article only for noncommercial purposes and as long as they give appropriate credit to the authors. They cannot distribute any modified material obtained by remixing, transforming or building upon this article.

See

https://creativecommons.org/licenses/by-ncnd/4.0/

\section{References}

1. Arney L, Yadav P. Improving Procurement Practices in Developing Country Health Programs. William Davidson Institute, University of Michigan, USA. 2014.

2. Onyango CJ. Effects of procurement planning on institutional performance: A Case study of Mombasa Law Court. International Journal of Science and Research (IJSR). 2012; 3(11): $446-455$.
3. Pharmacy Division. Updating of the Three-Year Rolling Procurement Plan for Essential Medicines and Health Supplies. 2010.

4. Jackson JG, Ombui K. Effects of procurement planning on service delivery in state research organization. Journal of Management. 2018; 5(2): 13261359.

5. Waswa Mutoro J, Nambuswa Makokha E, Namusonge G. Factors affecting procurement planning in Bungoma County in Kenya. European Journal of Business and Management. 2018; 10(10): 24-33.

6. Embrey M. Managing Access to Medicines and Health Technologies. 2014.

7. Ogubala R, Kiarie D. Factors affecting procurement planning in county governments in Kenya: a case study of Nairobi City County. International Journal of Economics, Commerce and Management. Nov 2014; 2(11).

8. Onyango CJ. Effects of procurement planning on institutional performance: A Case study of Mombasa Law Court. International Journal of Science and Research (IJSR). October 2014; 3(10): 2389 - 2408.

9. Irimu GW, Greene A, Gathara H, Maiana C, Mboiri-Ngacha D, Zurovac D, Santau M, Todd J, 
English M. Explaining the uptake of paediatric guidelines in a Kenyan tertiary hospital - mixed methods research. BMC Health Services Research. 2914;14:119.

10. Katimo GM. Factors hindering the Medical Stores Department in Preparation of Annual Procurement Plan., Open University of Tanzania. 2013.
11. Ministry of Health, Uganda. Management of Medicines and Health Supplies Manual. 2012. 